FUNDAÇÕES PÚBLICAS E O APERFEIÇOAMENTO DA GESTÃO MUNICIPAL

Elaine Antunes Fernandes ${ }^{1}$

Rodrigo Lopes Nabarreto ${ }^{2}$

\footnotetext{
${ }^{1}$ Licenciada em Letras pela Universidade de Taubaté (UNITAU) e Acadêmica de Ciências Jurídicas e Sociais (Direito) da Universidade Nove de Julho (UNINOVE). Rua Antônio Carvalhais, 128, São Paulo, SP, (11) 98197-7708. E-mail: elaine-af@ig.com.br

${ }^{2}$ Mestre em Direito pela Universidade Nove de Julho (UNINOVE). Especialista em Direito Empresarial UNIFMU, Direito do Trabalho UNICID e Direito Constitucional LFG. MBA em Administração Pública UNIDERP-Anhanguera. Graduado em Direito pela UNICAPITAL e Administração pela UNIFAI. Graduando em Gestão de Políticas Públicas na USP. Assistente da Presidência do Tribunal Regional do Trabalho da $2^{\text {a }}$ Região - São Paulo. Tutor da Escola Judicial do TRT/SP. Ex-Procurador do Município de Itaquaquecetuba. Professor de Direito Administrativo da Universidade Nove de Julho (Uninove). Endereço: Rua Joaquim Távora, 550, apto. 111A, São Paulo, SP, (11) 99545-8285. E-mail: nabarreto@usp.br
} 


\section{FUNDAÇÕES PÚBLICAS E O APERFEIÇOAMENTO DA GESTÃO MUNICIPAL}

\section{PUBLIC FOUNDATIONS AND THE IMPROVEMENT OF MUNICIPAL MANAGEMENT}

Resumo: O aumento da população e as atuais condições econômicas obrigam uma urgente revisão na forma pela qual os recursos públicos estão sendo geridos. Neste cenário, os Municípios possuem uma importante tarefa, haja vista as competências constitucionalmente estabelecidas. Por outro lado, nota-se que as fundações públicas, muito pouco exploradas pelas municipalidades, podem contribuir significativamente para uma melhoria na gestão. Objetivando alcançar a excelência, planejou-se a realização deste trabalho. Por intermédio de uma pesquisa quantitativa foi analisado o uso da fundação pública pelas capitais de Estados Brasileiros. Os dados colhidos revelaram a subutilização dessa figura. Por fim, como resultado da pesquisa, que se utilizou do método hipotético dedutivo, foi proposta a instituição de uma fundação pública municipal com objeto distinto do utilizado até os dias de hoje. Concluiu-se que a administração pública possui instrumentos jurídicos para alcançar a excelência administrativa no que se refere às suas atribuições. Palavras-chave: direito público municipal, fundação pública.

\footnotetext{
Abstract: The increase in population and current economic conditions require an urgent review in how public resources are being managed. In this scenario, the municipalities have an important task, given the constitutionally established powers. On the other hand, note that public foundations, very little explored by municipalities, can significantly contribute to improved management. In order to achieve excellence, it was planned this work. Through a quantitative research analyzes the use of public foundation the capitals of Brazilian states. The data collected revealed the underutilization of this figure. Finally, as a result of the research, which used the hypothetical deductive method was proposed to impose a municipal public foundation with distinct object used to this day. It was concluded that the government has legal instruments to achieve management excellence with regard to assignments you use.
}

Key words: public right municipal, public foundation. 


\section{FUNDAÇÕES PÚBLICAS E O APERFEIÇOAMENTO DA GESTÃO MUNICIPAL}

SUMÁRIO: 1. Introdução. 2. O Direito Municipal na Constituição. 3. A complexidade da governança. 4. A Administração indireta como ferramenta. 5. As Fundações Públicas Municipais. 6. Análise dos dados colhidos. 7. Proposta de Fundação Pública Municipal. 8. Conclusão. 9. Notas. 10. Referências bibliográficas. 11. Gráficos

\section{INTRODUÇÃO}

Em 2014, o Brasil passou a contar com 5.570 municípios divididos em 26 Estados e uma população de 202.768.562 pessoas, segundo o Instituto Brasileiro de Geografia e Estatística IBGE $^{\mathrm{i}}$.

Administrar recursos para tantas pessoas, em um país extenso e com diversas divisões políticas, não se constitui uma tarefa simples, exigindo preparo, organização e capacidade de gerenciamento.

O Estado, no âmbito federal, estadual e municipal, enfrenta, cotidianamente, problemas para alcançar excelência neste aspecto.

Para uma eficiente prestação das funções municipais, objetivando suprir suas necessidades, é preciso fazer uso de uma administração moderna e perspicaz.

Estabelecer as prioridades para se administrar é uma tarefa árdua, especialmente em razão da urgência que algumas situações exigem, entretanto, essa conduta torna-se fundamental para que o sucesso seja alcançado. 
Assim, definir estratégias de ação inteligentes e, efetivamente, implantá-las aparenta ser o único caminho apto a levar ao desenvolvimento político, econômico e social.

Em diversas ocasiões, os municípios não possuem capital intelectual capaz e disponível, tampouco dados estatísticos reais, para enfrentar questões relativas às definições e execuções de políticas públicas.

Tendo em vista a importância dos municípios e a relevância de suas políticas públicas para o desenvolvimento da sociedade, produziu-se esta pesquisa, objetivando encontrar novos instrumentos capazes de maximizar os resultados advindos da administração pública municipal.

Como ente federativo, a Municipalidade é regida pelas normas do Direito Público, que se apóiam no tripé principiológico da supremacia do interesse público sobre o individual, a indisponibilidade do interesse público e a legalidade.

Sem perder de vista o respeito a estes princípios, a Municipalidade deve atender a uma miríade de serviços públicos, cuja forma de administração, quanto a essas prestações, pode se operacionalizar de várias maneiras.

Nessa pesquisa, inicialmente, refletiu-se sobre o Direito Municipal e a Administração Pública, em seguida foram analisados alguns aspectos ligados à governança, prosseguindo com a verificação das formas em que as Fundações Públicas vêm sendo utilizadas pelos municípios, e, após, apresentou-se o levantamento e análise dos dados colhidos.

Para tanto, utilizando o método indutivo, foram pesquisadas as capitais dos estados, que dada sua importância política acredita-se que apresentam maiores probabilidades de disporem de fundações, uma vez que normalmente são as cidades com maior contingente populacional, principalmente em regiões menos desenvolvidas economicamente e maior disposição de recursos, o que permitiria uma visualização mais clara da forma de uso das fundações. 
Considerando a importância atual da Internet e da confiabilidade das informações prestadas pelos sites oficiais, essa foi ferramenta eleita para essa coleta inicial de dados.

Ao final, concluiu-se que, (1) por meio da Administração Pública Indireta, precisamente, por intermédio das Fundações Públicas, é possível construir ferramentas para se atingir a "excelência na administração pública" e que, (2) a obtenção, tratamento e análise de dados estatísticos é de fundamental importância para a definição e implantação de toda e qualquer política pública municipal.

\section{O DIREITO MUNICIPAL NA CONSTITUIÇÃO}

A Carta Republicana de 1988 inovou ao considerar os Municípios como entes federativos, embora o artigo 68 da Carta de 1891 já tenha se referido à autonomia municipalii .

A Constituição Federal de 1988 ao incluir os municípios no rol dos entes federativos, corrompeu a Teoria Geral do Federalismo iii, afinal, esta sempre previu uma federação de Estados e não uma federação de municípios (BULOS, 2014, p. 940-941).

Neste sentido, é salutar destacar que a Federação Brasileira possui características peculiares que não podem ser desprezadas.

Cabe frisar que, atualmente, as municipalidades contam com a capacidade de autogoverno, autoadministração e autolegislação.

É certo que os municípios devem atender a uma série de serviços públicos, conforme previsão contida no artigo 30 da Carta Magna, especialmente em razão de sua competência em satisfazer as necessidades de interesse local. 
Segundo Diogo de Figueiredo, a noção funcional de serviço público parte do princípio de que algumas necessidades coletivas não podem ser satisfeitas plenamente se não forem asseguradas ou assumidas pelo Poder Público, de maneira que essas atividades da administração visam atender a interesses coletivos secundários, que apesar de serem considerados por lei como de interesse público, na realidade são de aproveitamento individual (FIGUEIREDO, 2014, p.470).

Maria Sylvia Zanella Di Pietro, por sua vez, define o serviço público como:

(...) toda atividade material que a lei atribui ao Estado para que a exerça diretamente ou por meio de seus delegados, com o objetivo de satisfazer concretamente às necessidades coletivas, sob regime jurídico total ou parcialmente público (DI PIETRO, 2014, p. 107).

Em que pese a gama de atribuições, é fato que, muitas vezes, o Município não consegue desempenhar suas funções administrativas, sem apoio da União e dos Estados. Persevera essa situação na educação, saúde pública, implantação de complexos industriais, entre outros (BRAZ, 2010, p. 92).

Diversos são os fatores que impossibilitam o desempenho eficiente da função administrativa, sendo certo que a falta de capacidade gestora e a ausência de dados estatísticos reais contribuem significativamente para que isso ocorra, como será visto no desenvolver de nosso trabalho.

\section{A COMPLEXIDADE DA GOVERNANÇA}

Como mencionado anteriormente, governar não é tarefa fácil, mormente diante das condições materiais e políticas dos municípios brasileiros.

Inicialmente, antes de enfrentar a problemática municipal, compete diferenciar governança de governabilidade. Esta é concernente ao poder político, sua legitimidade para governar, ser reconhecida pela população e seus representantes. Aquela, por sua vez, refere-se à capacidade de implementação de políticas públicas que atendam às necessidades da população. 
Neste estudo, importa a capacidade de governança, pois por meio dela, busca-se maior eficiência e eficácia na prestação de serviço à população e gerenciamento do patrimônio público.

Insta destacar que a ideia de governança relaciona-se à competência técnica, tratando-se de um instrumento que envolve diversas habilidades, tais como gerencial, financeira e técnica propriamente dita, além de ser diretamente afetada pela capacidade dos servidores públicos.

Diante de suas características, nesse contexto de governança pública, surgiu a necessidade de investimento na capacitação dos servidores públicos, a qual inclui a participação do mercado e da sociedade civil nos atos decisórios, nascendo daí alianças, acordos, parcerias e cooperações entre governo, mercado e sociedade (PALUDO, 2010, p.145-146).

A governança, portanto, diz respeito a uma administração eficiente e a um melhor atendimento ao cidadão, sinalizando, no âmbito municipal, ao fortalecimento do governo local, sendo imprescindível a criação de novos canais de participação da sociedade e uma maior capacidade de coordenação, a fim de se obter congruência e uniformidade nas políticas públicas.

Essa coordenação deve possuir como escopo um projeto coletivo cujo objetivo deve ser o de harmonizar as várias demandas sociais existentes (DINIZ, 1997, p.40-41).

Para que se possam harmonizar as várias demandas sociais existentes faz-se necessário que as ações públicas sejam estrategicamente definidas.

Assim, os Municípios devem ter em seus quadros recurso humano capacitado para definir estrategicamente políticas públicas. Entretanto, essa tarefa não é fácil.

A complexidade e dinâmica da máquina pública torna imperativa a adoção de novas práticas objetivando uma melhoria contínua da gestão.

Sem dúvida, essa construção deve se dar de forma cooperada, pois engloba tanto o trabalho conjunto de atores públicos, comunitários e privados, quanto também novas formas de transferência 
de serviços para grupos privados e comunitários (KISSLER, Leo; HEIDEMANN, Francisco, 2006, p. 100)

A construção de políticas públicas é fundamental para o desenvolvimento municipal, devendo ser elaborada com extrema responsabilidade e com a utilização das melhores técnicas existentes nas ciências jurídicas e administrativas.

\section{A ADMINISTRAÇÃO INDIRETA COMO FERRAMENTA}

A Administração Pública divide-se em Direta e Indireta. A primeira envolve a União, Estados, Distrito Federal e Municípios, enquanto que a Indireta é composta pelas autarquias, fundações públicas, as sociedades de economia mista, as empresas públicas, os consórcios públicos e as empresas concessionárias e permissionárias de serviços públicos (DI PIETRO, 2014, p.493).

Diante de suas características peculiares, a figura das Fundações Públicas foi adotada para o desenvolvimento deste trabalho.

Neste ponto, cabe destacar que as Fundações Públicas são entidades dotadas de personalidade jurídica conferida por lei específica, com autonomia política e financeira, sem fins lucrativos, cujo patrimônio deverá estar destinado a uma finalidade social.

Sua área de atuação será de caráter social. Nessa classificação encontram-se aquelas que buscam o benefício coletivo, tais como educação, saúde, esporte, trabalho e outras (SIMÃO, 2014, p.140).

As fundações de direito público usufruem de privilégios próprios, tais como procedimento especial de execução ${ }^{\text {iv }}$, impenhorabilidade de seus bens, juízo privativo ${ }^{\mathrm{v}}$, prazos processuais estendidos, duplo grau de jurisdição, imunidade tributária quanto aos impostos referentes ao patrimônio, renda ou serviços ${ }^{\text {vi }}$. Acrescente-se ainda a presunção de veracidade, imperatividade e 
executoriedade de seus atos, além de outras prerrogativas previstas em leis específicas de cada entidade (DI PIETRO, 2014, p.533).

\section{AS FUNDAÇÕES PÚBLICAS MUNICIPAIS}

Os dados obtidos nesta pesquisa, relativos às fundações públicas municipais, foram colhidos nos sites das capitais de Estados e do Distrito Federal.

Com base nas informações coletadas nos sítios de 26 capitais e do Distrito Federal, percebeu-se que $20 \%$ das fundações públicas encontram-se situadas no sudeste, 10,90 no sul, 16,36 no centro-oeste, $25,45 \%$ no note e $27,27 \%$ no nordeste, conforme gráfico 01 .

À primeira vista, pode-se imaginar que as regiões estão relativamente equilibradas quanto ao número de fundações públicas municipais existentes, contudo, essa percepção inicial não é verdadeira.

Proporcionalmente ao número de Estados por região, uma distribuição equilibrada seria a seguinte: o sudeste contaria com 14,76\% equivalente a 4 Estados; o nordeste com 33,21\% referente a 9 Estados; o norte com 25,83\% relativo a 7 Estados; o centro-oeste com 14,76\% condizentes com 3 Estados e o distrito federal e o sul com 11,07\% concernente a 3 Estados, conforme gráfico 02.

Sobreleva-se, portanto, que as regiões sudeste e centro-oeste possuem mais fundações por Estado que as demais regiões.

Em uma perspectiva por região e área de atuação, na coleta de dados, foram consideradas as seguintes divisões: foco em educação/ pesquisa; cultura/ patrimônio histórico; meio-ambiente; esportes/ educação ligada ao desporto; assistência Social/ Inclusão Social; zoológicos; saúde/ Pesquisas ligadas à saúde e outras áreas de atuação.

Em regra, observou-se que a fundação pública municipal possui como objeto a atuação em mais de um campo. 
Da pesquisa realizada, conforme as classificações apresentadas e considerando as atividades preponderantes de cada fundação pública, identificou-se que, em termos percentuais, concernente à totalidade regional, a região sudeste possui 18,18\% ligadas à educação/pesquisa; mesmo percentual quanto às categorias meio ambiente; zoológicos e outras não especificadas, enquanto que 27,27\% relacionam-se a assuntos ligados à cultura/ patrimônio. Destaca-se a cidade do Rio de Janeiro como a capital da região com maior número de fundações públicas municipais.

O Nordeste é a região com a maior quantidade de entidades funcionais, devido à quantidade de Estados membros localizados na região geográfica, sendo 53,33\% ligadas à cultura/patrimônio; 20\% à assistência social/inclusão social; 13,33\% ligadas à saúde/pesquisas relacionadas à saúde e 13,33\% referentes a outras áreas não especificadas. Teresina é a capital que mais ostenta fundações.

A região norte possui 7,14\% ligadas à educação/pesquisa; mesmo percentual para as áreas relativas ao meio ambiente e esporte/educação ligada ao desporto; 28,57\% atuam na área de cultura/patrimônio; 14,28\% em assistência social/inclusão social e 35,71\% em outras áreas não especificadas. Quantitativamente, Belém é o município com mais fundações públicas municipais.

No centro-oeste, que incluiu o Distrito Federal, foi constatado que 22,22\% das fundações públicas referem-se à educação/pesquisa; mesmo percentual para as áreas de assistência social/ inclusão social e saúde/pesquisas relacionadas à saúde; 11,11\% referem-se à área cultural/patrimônio, apresentando-se o mesmo percentual para as áreas esporte/educação ligada ao desporto e zoológico. Das capitais dessa região, Brasília é a cidade que mais faz uso das fundações públicas.

A região sul, que contém menos Estados membros, está dividida em 33,33\% atuantes na área cultural/patrimônio; 16,66\% na área de meio ambiente e mesmo percentual para as áreas de esporte/educação para o desporto; assistência social/inclusão social e outras áreas não 
especificadas. Florianópolis é a municipalidade de destaque concernente ao número de fundações nessa região do país.

\section{ANÁLISE DOS DADOS COLHIDOS}

As informações coletadas mostram que o uso das fundações públicas municipais é variado, entretanto, ainda, muito pouco explorado.

A existência de fundações públicas estaduais e federais ou privadas pode influenciar os municípios na escolha do objeto de suas entidades jurídicas.

A opção pela criação de "Fundos", ao invés de fundações, a cooperação nas áreas de atuação com outras entidades sem fins lucrativos e fatores de ordem econômica e política, motivam a escolha dos objetos.

Há ainda de ser considerado que a atividade fundacional de um município pode irradiar seus efeitos direta ou indiretamente em localidades próximas, o que destaca a importância de sua atuação.

Nesse sentido, destacam-se a Fundação Instituto das Águas no município do Rio de Janeiro, atuante na área de manutenção hídrica, e a Fundação de Desenvolvimento Habitacional de Fortaleza, direcionada à redução do déficit habitacional.

Os dados colhidos e a análise realizada apontaram para uma variedade de atuações possíveis por meio dessa entidade administrativa, demonstrando o quão plástica é essa forma descentralizada.

Essa característica permite a criação de novas formas de utilização em busca do bem comum, constituindo assim um promissor instrumento com potencial a ser direcionado à concretização de governança adequada a uma Administração Pública Municipal eficiente. 


\section{PROPOSTA DE FUNDAÇÃO PÚBLICA MUNICIPAL}

Observe-se que a demanda por serviços municipais tende a aumentar à medida que sua população cresce, em contrapartida, o atual cenário econômico mundial, exige uma minimização de recursos com uma maximização de resultados.

Essa busca por equilíbrio e eficiência clama, especialmente, por servidores e administradores públicos bem capacitados e conhecedores dos problemas regionais que necessitam de maior atenção e solução imediata.

A sociedade não mais tolera qualquer amadorismo na gestão pública, a cada dia que passa exige-se uma conduta extremamente profissional por parte do gestor público.

É certo que as Fundações Públicas devem atender às necessidades sociais, desprovidas de qualquer interesse lucrativo.

Desta forma, considerando as características peculiares desses entes, os anseios da sociedade, a carência da administração pública, no tocante ao capital humano, a necessidade de uma melhor performance administrativa, o atual cenário econômico e político, propõe-se a criação de uma fundação que objetive a colheita de dados estatísticos reais da sociedade, a análise das informações colhidas, a elaboração de pareceres estratégicos para definição de políticas públicas municipais diretamente relacionadas às necessidades identificadas e a específica capacitação de servidores e administradores públicos responsáveis pelo planejamento e execução de políticas públicas.

Esse aperfeiçoamento da gestão municipal, compreendido aqui como um norteamento e atualização de técnicas de administração pública de forma a melhor atender os interesses da coletividade, que são altamente mutáveis, e capacitação técnica devem ser realizados progressiva e 
continuamente, isto porque, no âmbito municipal, não é raro encontrar uma administração despreparada para lidar com todas as questões complexas que surgem ao longo de uma gestão.

Frise-se que o objeto "capacitação de servidores" foi estabelecido pelo município do Rio de Janeiro, por intermédio da Fundação João Goulart e pelo município de Porto Velho, com a Fundação Escola do Servidor Público Municipal de Porto Velho.

A proposta derivada desta pesquisa, entretanto, vai além, uma vez que sugere a instituição de uma fundação pública que obtenha dados estatísticos, analise-os, sugira políticas públicas vinculadas às informações obtidas e, a partir disto, execute o aperfeiçoamento e a capacitação dos gestores e servidores públicos municipais para que tenham condições de implementação.

O objetivo da fundação pública municipal não seria apenas ofertar cursos de capacitação e/ou reciclagem, mas realizar pesquisas técnicas sobre os interesses e problemas locais.

A fundação pública municipal, dotada de capital humano especializado, poderia fomentar e conduzir grupos de debates entre os administradores públicos e grupo de debates abertos à participação popular, sempre baseados em dados obtidos nas necessidades de cada bairro ou grupo de pessoas (idosos, gestantes, portadores de necessidades especiais, entre outros).

O foco não seria apenas a transmissão de informações, como suas fundações irmãs, mas incentivar a criação de propostas para solução de problemas, por meio da utilização de capital intelectual especializado no assunto, capaz de identificar pontos fortes e fracos dos projetos.

Esses projetos prosseguiriam como metas anuais a serem seguidas pela administração pública municipal.

Ao final de cada ano, com o auxílio da Fundação Pública Municipal instituída, os Conselhos Municipais agiriam como fiscalizadores da efetividade das medidas tomadas para a concretização do projeto, da política pública e das metas estabelecidas ${ }^{\mathrm{vii}}$. 
Dessa maneira, diversos objetivos municipais seriam alcançados: atendimento do interesse local; aprimoramento da prestação dos serviços públicos ao visar aprimoramento dos servidores/gestores, aperfeiçoamento de técnicas estratégias, correção de falhas na implementação; possibilidade de inovações em áreas diretamente ligadas ao desenvolvimento social, econômico e ambiental com o fomento de debates e disseminação de conhecimento não apenas aos servidores e administradores públicos, mas também à população; incentivo à cidadania; proteção ao patrimônio público decorrente do melhor preparo dos agentes; aproximação do Poder Público e do cidadão; maior transparência das medidas tomadas ao logo da gestão municipal e uma governança mais produtiva.

Essa cooperação entre Município, Fundação Pública Municipal e Conselho Municipal poderia ser ampliada, incentivando a instituição de outras fundações parceiras (cuja instituição se daria baseada nas necessidades debatidas nessa fundação pública estratégica que aqui se propõe, de forma que o interesse coletivo a que se destina seja realmente direcionado à demanda daquela comunidade) ou mesmo buscando apoio de fundações privadas já existentes e outras associações sem fins lucrativos ${ }^{\text {viii }}$.

Naturalmente, despicienda a criação de uma Fundação Pública Municipal desse porte para cada municipalidade, sendo bastante razoável a formação de um consórcio entre municípios próximos para tal finalidade.

Isto porque, certos assuntos, que ontem só diziam respeito à vida de um município, podem passar a interessar a diversos. Essa variação, no tempo, da área territorial sobre a qual repercute um grande número de problemas administrativos torna muito relativa a noção de peculiar interesse do município, ou de interesse local (LEAL, 2012, p. 75).

O ponto chave, então, seria se buscar uma forma de vinculação dos projetos definidos na forma de metas, a fim de se garantir sua execução, partindo dos projetos nascidos dos debates promovidos pela Fundação Pública, o que talvez permitisse alcançar a excelência administrativa. 
Segundo Maurício Biazotto Cortes ${ }^{\mathrm{ix}}$, a busca pela excelência na gestão tem sido o objetivo principal de praticamente todas as corporações empresariais ao redor do mundo, como forma de otimizar recursos, obter melhores resultados, atender bem os clientes, ou seja, estabelecer um círculo virtuoso onde todos se beneficiam, sendo certo que, no setor público não poderia ser diferente. A excelência na gestão deve ser uma obrigação dos governantes, devendo ser o item número um no rol de prioridades administrativas, visto que os recursos empenhados são frutos da contribuição de cada cidadão que trabalha e contribui por meio dos impostos.

\section{CONCLUSÃO}

Na busca por uma excelência administrativa e uma gestão municipal eficiente, todos os recursos disponíveis devem ser analisados de modo a melhor atender aos interesses sociais.

A pesquisa realizada analisou o uso de um desses recursos e ressaltou o fato de que as fundações públicas são subutilizadas pelas municipalidades, com pouco aproveitamento das prerrogativas que dispõem.

Considerando que, a qualidade da gestão está diretamente ligada ao nível qualitativo da prestação dos serviços à comunidade, a preocupação em encontrar novas formas de implementá-la é justificável.

O Município, nesse contexto, figura em posição estratégica e relevante, pois “... representa a ligação dialógica entre governo e sociedade...” (ZENI E GONÇALVES, 2010, p.7292).

Destarte, com administradores preparados e uma sociedade politicamente ativa, estaremos criando condições de perseguir os objetivos elencados no artigo $3^{\circ}$ da Constituição Federal. 


\section{NOTAS}

\footnotetext{
' http://7a12.ibge.gov.br/voce-sabia/curiosidades/municipios-novos e http://g1.globo.com/economia/noticia/2014/08/brasil-tem-202768562-habitantes-estima-ibge.html ${ }^{\text {ii }}$ Art 68 - Os Estados organizar-se-ão de forma que fique assegurada a autonomia dos Municípios em tudo quanto respeite ao seu peculiar interesse.

iii Forma de organização política, de origem norte-americana, em que convivem, de forma harmônica e sistemática, 2 governos distintos: o federal e o estadual. Aos Estados-membros é assegurada sua autonomia constitucional perante a União, enquanto esta possui soberania e personalidade jurídica internacional.

iv artigo 100 da Constituição Federal e artigos 730 e 731 do CPC

${ }^{\vee}$ artigo 109 da Constituição

vi artigo 150, VI, a e $\$ 2^{\circ}$ da Constituição Federal/1988

vii Verifica-se que a atribuição de fiscalização de programas e projetos já se encontra definida para os Conselhos Municipais, conforme Resolução no 13, de 16 de junho de 2004 e na Resolução ${ }^{\circ}$ 25, de 18 de março de 2005, do ConCidades e nas deliberações da $2^{\mathrm{a}}$ Conferência Nacional das Cidades. (Ministério das Cidades, 2006, p.10).

viii Estes são outros recursos que podem e devem ser utilizados para o desenvolvimento social, mas que fogem ao objeto do presente estudo.

viii Artigo apresentado no XIV Congreso Internacional del CLAD sobre la Reforma del Estado y de la Administración Pública, Salvador de Bahia, Brasil, 27 - 30 oct. 2009
}

\section{REFERÊNCIAS BIBLIOGRÁFICAS}

ARAGÃO, Cecília Vescovi. Burocracia, eficiência e modelos de gestão pública: um ensaio. São Paulo: Revista do Serviço Público. Ano 48, n. 3 (Set-Dez/1997). Brasília: ENAP, 1997.

BRAZ, Petrônio. Direito Municipal na Constituição. $7^{\text {a }}$ ed. Leme: J H Mizuno, 2010.

BONAVIDES, Paulo. Teoria do estado. 4. ed. São Paulo: Malheiros, 2003.

BULOS, Uadi Lammêgo. Curso de Direito Constitucional. 8a ed. São Paulo: Saraiva, 2014

CRETELLA JÚNIOR, José. Direito administrativo brasileiro. 2. Ed. Rio de Janeiro: Forense, 2000.

CKAGNAZAROFF, Ivan Beck. Reflexões sobre estratégias de governança local. Revista Gestão e Sociedade. GES - v 3, n 5, jan./jun. 2009 CEPEAD/FACE/UFMG. Disponível em: www.gestaoesociedade.org/gestaoesociedade/article/view/687

DINIZ, Eli. Crise, reforma do Estado e governabilidade. Rio de janeiro: Fundação Getúlio Vargas, 1999.

DI PIETRO, Maria Sylvia Zanella. Direito Administrativo. 27ª ed. São Paulo: Atlas, 2014. 
FERNANDES, Claudio Roberto; SILVA, Ezequiel José da; TEIXEIRA, Thyago Borim; SILVERIO, Rosana de Souza; FERNANDES, Kassio Stenio Alves; SCALCO, Virginia Maria Ferreira; FERNANDES, Daniele Domingues da S.; CAPRONI, Pedro. A governança $e a$ governabilidade na atual gestão pública brasileira. In: Âmbito Jurídico, Rio Grande, XV, n. 106, nov 2012. Disponível em: <www.ambitojuridico.com.br/site/index.php/?n_link=revista_artigos_leitura\&artigo_id=12469\&revista_caderno= 4>. Acesso em fev 2015.

JUSTEN FILHO, Marçal. Curso de Direito Administrativo. 4. ed. São Paulo: Saraiva, 2009.

KISSLER, Leo; HEIDEMANN, Francisco. Governança pública: novo modelo regulatório para as relações entre Estado, mercado e sociedade. Jun. 2006. Scielo. Disponível em: www.scielo.br/scielo.php?pid=S0034-76122006000300008\&script=sci_arttext.

LEAL, Victor Nunes. Coronelismo, Enxada e Voto. $4^{\mathrm{a}}$ ed. São Paulo: Companhia das Letras, 2012.

LIMA JUNIOR, Olavo Brasil de. As reformas administrativas no Brasil: modelos, sucessos e fracassos. Brasília: Revista do Serviço Público. Ano 49, número 2, abr-jun/1998.

MEIRELLES, Hely Lopes. Direito Administrativo Brasileiro. 23. ed. São Paulo: Malheiros, 1998.

MOREIRA NETO, Diogo de Figueiredo. Curso de Direito Administrativo. 16 ed. Rio de Janeiro: Ed Forense, 2014.

NOHARA, Irene Patrícia. Reforma administrativa e burocracia: impacto da eficiência na configuração do direito administrativo brasileiro. São Paulo: Atlas, 2012.

PALUDO, Augustinho Vicente. Administração Pública: teoria e questões. Rio de Janeiro: Elsevier, 2010.

SIMÃO, Calil. Fundações Governamentais. São Paulo: Editora Revista dos Tribunais, 2014.

SPITZCOVSKY, Celso. Direito administrativo. 4. ed. São Paulo: Edições Paloma, 2003.

ZENI, Bruna Schlindwein; GONÇALVES, Diego Marques. Poder Local e Participação Popular na Administração Pública: Reflexões acerca dos Conselhos Municipais no Direito Brasileiro. Trabalho publicado nos Anais do XIX Encontro Nacional do CONPEDI realizado em Fortaleza - 
CE nos dias 09, 10, 11 e 12 de Junho de 2010. Pp.7284-7297. Disponível em: www.conpedi.org.br/manaus/arquivos/anais/fortaleza/3909.pdf

\section{GRÁFICOS}

\section{Gráfico 01}

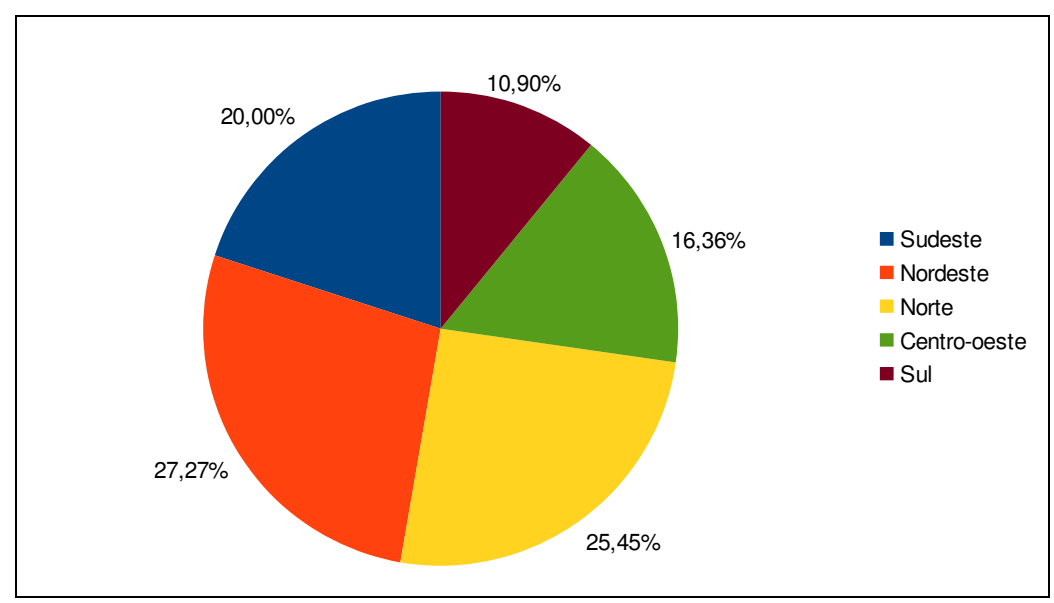

Gráfico 02

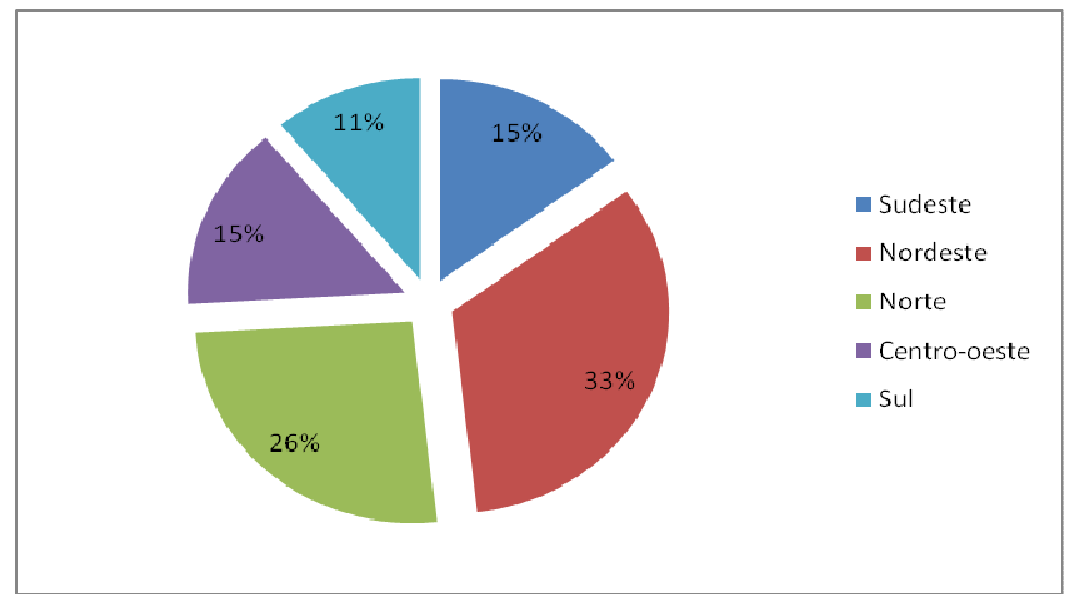

